\title{
Strategic Maneuvering in Treatment Decision-Making Discussions: Two Cases in Point
}

\author{
Nanon Labrie
}

Published online: 31 August 2011

(C) Springer Science+Business Media B.V. 2011

\begin{abstract}
Over the past decade, the ideal model of shared decision-making has been increasingly promoted as the preferred standard of doctor-patient communication in medical consultation. The model advocates a treatment decision-making process in which the doctor and his patient are considered coequal partners that carefully negotiate the treatment options available in order to ultimately reach a treatment decision that is mutually shared. Thereby, the model notably leaves room for-and stimulates - argumentative discussions to arise in the context of medical consultation. A paradigm example of a discussion that often emerges between doctors and their patients concerns antibiotics as a method of treatment for what is presumed to be a viral infection. Whereas the doctor will generally not encourage treatment with antibiotics, patients oftentimes prefer the medicine to other methods of treatment. In this paper, two cases of such antibiotic-related discussions in consultation are studied using insights gained in the extended pragma-dialectical theory to argumentation. It is examined how patient and physician maneuver strategically in order to maintain a balance between dialectical reasonableness and rhetorical effectiveness, as well as an equilibrium between patient participation and evidence-based medication, while arguing a case for and against antibiotics respectively.
\end{abstract}

Keywords Pragma-dialectics - Strategic maneuvering · Doctor-patient consultation $\cdot$ Shared decision-making $\cdot$ Antibiotics

\footnotetext{
N. Labrie $(\bowtie)$

Institute of Communication and Health, University of Lugano, Lugano, Switzerland e-mail: nanon.labrie@usi.ch
} 


\section{Introduction}

Although reflection on the interactive aspects of doctor-patient consultation is undoubtedly as old as medicine itself and recognition of its therapeutic power goes back to Hippocrates and Plato (Heritage and Maynard 2006, p. 354), ${ }^{1}$ the past decades have seen an increased interest in the communicative interaction between the physician and his patient. Not only within the field of medicine itself, scholars and practitioners alike have paid significant attention to the communication between doctors and their patients (e.g., Charles et al. 2003; Edwards and Elwyn 2009; Ong et al. 1995; Roter and Hall 1989, 2006), but also within the broader field of communication studies the multiplex relationship between the physician and his patient has become a focal point (e.g., Heritage and Maynard 2006; Maynard and Heritage 2005; Stivers 2002).

In the field of argumentation studies, and within the pragma-dialectical approach to argumentation (van Eemeren and Grootendorst 1984, 1992, 2004) more specifically, recently, an attempt has been made to characterize the interaction between a doctor and his patient as an argumentative activity type (van Eemeren 2010). It has been aimed to demonstrate that doctor-patient consultation can be analyzed as an inherently argumentative exchange in which the doctor and his patient interact as discussants that strive to convince each other of the acceptability of their own pre-existing views with regard to diagnosis, prognosis, and treatment options (Pilgram 2009; Snoeck Henkemans 2011).

This paper aims to add to this pragma-dialectical endeavor by analyzing the argumentative discourse of doctors and their patients in medical consultation that is aimed at shared decision-making. Shared decision-making is a mutuality-based approach to doctor-patient communication that has been increasingly promoted over the past decade. The model advocates a medical decision-making process in which both the doctor and the patient actively take part as coequal discussion partners, negotiating treatment options, in order to enhance health outcomes and patient adherence (e.g., Charles et al. 1997, 1999; Charles et al. 2003; Edwards and Elwyn 2009).

In an analysis of two pediatric consultations in which a doctor is presented with a child that is suffering from an upper respiratory tract infection, it will be studied how doctors and their patients, in this specific argumentative context, maneuver strategically (van Eemeren 2010) in order to resolve their difference of opinion regarding treatment. That is, it will be analyzed how both physician and patient aim to maintain a balance between the (dialectical) reasonableness and the (rhetorical) effectiveness of their argumentative moves while striving to convince their opponent of the acceptability of their own treatment preference. While the doctor, in

\footnotetext{
1 The idea that the doctor and his patient must engage in a genuine dialogue in order to achieve successful medical therapy, is prominent in Plato's Laws, Book IV and IX, where a distinction is made between "empirical physicians, who practice medicine without science" and "gentlemen physicians": The gentleman physician "[...] carries his enquiries far back, and goes into the nature of the disorder; he enters into discourse with the patient and with his friends, and is at once getting information from the sick man, and also instructing him as far as he is able".
} 
both cases, prefers treatment with acetaminophen, the parent requests a course of antibiotics.

In particular, it will be analyzed how the strategic maneuvers employed by doctor and patient are inherently shaped by, and connected to, the shared decision-making ideal. In doing so, first it should be clarified what exactly it means for doctors and patients to share treatment decisions in consultation. What distinguishes the shared decision-making model from other models of doctor-patient interaction? This question will be addressed in Sect. 2 of this paper. In Sect. 3, the concept of strategic maneuvering will be discussed, starting from the pragma-dialectical theory of argumentation. After that, in Sect. 4, an argumentative characterization of medical consultation aimed at shared decision-making will be provided, taking into account the contextual norms, rules, and regulations that shape doctors' and patients' argumentative discourse. In Sect. 5, finally, the two cases of doctor-patient disagreement regarding treatment with antibiotics will be studied in depth in an effort to answer the main question posed in this paper: In the context of medical consultation, how may a physician and his patient maneuver strategically in order to maintain a balance between dialectical reasonableness and rhetorical effectiveness, as well as an equilibrium between patient participation and evidence-based medication, while arguing their case for and against antibiotics respectively?

\section{Shared Decision-Making in Medical Consultation}

According to Roter and Hall (2006), the relationship between a doctor and his patient is characterized by the expectations each holds with regard to the other party's conduct during consultation. Central to these expectations are doctors' and patients' varying perspectives on authority and autonomy (2006, p. 23). While some regard the physician as the undisputable authority because of his medical expertise, others consider the patient an autonomous entity holding the fundamental right to make all decisions that affect his personal health. Again others are in favor of simultaneous physician authority and patient autonomy.

Roter and Hall (2006) suggest that-as a result of these varying perspectivesfour principal forms of the doctor-patient relationship can be distinguished (Table 1): Paternalism, consumerism, default, and mutuality. It is claimed that in each of these forms of doctor-patient interaction, the power relation between the physician and his patient is divided differently.

Paternalism (upper-right quadrant) is traditionally regarded as the standard form of doctor-patient interaction. Although it is the most prevalent of the four

Table 1 Four forms of the doctor-patient relationship (Roter and Hall 2006)

\begin{tabular}{lll}
\hline Patient control & \multicolumn{2}{l}{ Physician control } \\
\cline { 2 - 3 } & Low & High \\
\hline Low & Default & Paternalism \\
High & Consumerism & Mutuality \\
\hline
\end{tabular}


prototypes, it is not necessarily the most efficient or desirable model of doctorpatient relations. Paternalism refers to a model of communication in which the physician directs care and dominates the decision-making process. The medical condition is defined in medical terms and the patient's voice is largely absent (Roter and Hall 2006). It is assumed that the patient's preferences are similar to those of the doctor. After all, it is 'the doctor who knows best'.

At the other end of the spectrum (lower-left quadrant), the prototype of doctorpatient relationship referred to as consumerism can be found. The ideal model of consumerism, reversing the traditional paternalistic role-division, is characterized by high patient control. That is, the patient sets the agenda as well as the consultation goals. Moreover, it is the patient (or consumer) who directs the decision-making process. The physician's role is limited to that of a consultant (or provider) who has the obligation to provide the essential information and services related to the patient's preferences while refraining from jargon and remaining within the bounds of the profession (Roter and Hall 2006). Mimicking the societal trend of consumerism, medical consultation is thereby redefined as a marketplace transaction.

The upper-left quadrant of Table 1 represents a default relationship between the doctor and his patient. Default relationships are characterized by a lack of control by both doctor and patient and are far from perfect (Edwards and Elwyn 2009). Patient and physician expectations may be at odds, common goals unclear, patient values neglected, and the division of roles may be uncertain. Furthermore, the register and jargon used by physician and patient are likely to clash. As a result, the communication may come to a dysfunctional standstill, a relationship default (Roter and McNeilis 2003), and without an intervention the medical relationship may fail permanently. In sharp contrast to the other three prototypes, the default relationship —although represented in empirical reality —is not regarded as an ideal model.

Stressing the importance of equal physician and patient control, the prototype of mutuality (lower-right quadrant) proposes a modern alternative to the extremes of paternalism and consumerism and the defective default model (Roter and Hall 2006). It is within the realm of mutuality that shared decision-making takes place. This means that all goal and agenda setting and treatment decisions are the result of careful negotiation between the doctor and his patient. ${ }^{2}$ Following the most commonly cited conceptualization of shared decision-making, the practice of shared decision-making can be concisely defined as follows:

[Shared decision-making concerns the] involvement of both the patient and the doctor, a sharing of information by both parties, both parties taking steps to

\footnotetext{
2 The concept of shared decision-making and its focus on enhancement of patient choice (Charles et al. 1999 , p. 658) requires that both physician and patient perceive that there are indeed treatment options to choose from. Aside from a choice between two alternative kinds of treatment (e.g., radiotherapy or chemotherapy), which according to Gwyn and Elwyn qualifies as a situation of true equipoise, there is always also a choice between doing nothing and doing something (Charles et al. 1999). According to Gwyn and Elwyn (1999), a situation of equipoise should exist in order for shared decision-making to take place. Yet, in practice, this is not always the case. When antibiotics are requested, for example, it could be argued that often a situation of pseudo-equipoise exists as the patient assumes that antibiotics form a suitable treatment option, while medical evidence counters this conviction.
} 
build a consensus about the preferred treatment, and reaching an agreement about which treatment to implement ${ }^{3}$ (Charles et al. 1997).

Whereas the doctor is seen to hold highly advanced medical expertise, the patient is assumed to possess a unique knowledge of his own health and his preferences for treatments, health states, and outcomes. As a result, doctors' and patients' viewpoints and roles are considered to be highly distinct yet of equal importance.

A relational model of mutuality in which the physician and his patient negotiate their decisions implies that-aside from a mere exploration of expectations and ascertainment of prior knowledge and preferences-both parties make a commitment to resolve any disagreement that arises during consultation in a reasonable and mutually respectful manner. Thereby, in contrast to the other models, the model of shared decision-making notably leaves room for, and even encourages, argumentative discussions to arise during medical consultation.

A paradigm example of such an argumentative discussion in doctor-patient consultation is the discussion that emerges subsequent to a patient's request for antibiotics to treat an upper respiratory tract infection caused by a viral infection. Whereas patients often consider antibiotics to be a miracle drug, doctors are generally hesitant to prescribe the medicine because of the disadvantages it poses (e.g., antibacterial resistance, undesirable side-effects). When a patient asks for antibiotics to treat what is presumed to be a viral upper respiratory tract infection, therefore, a shared treatment decision may need to be negotiated. Following the mutuality-based shared decision-making model, the patient and his doctor will each attempt to reasonably and effectively convince each other of the acceptability of their standpoint - a standpoint for and against antibiotics, respectively. An argumentative discussion can be said to have arisen.

\section{A Pragma-Dialectical Approach to Argumentative Discourse}

In the pragma-dialectical theory of argumentation, argumentation is studied as a mode of discourse characterized by the use of language for resolving a difference of opinion (van Eemeren and Grootendorst 1984, 1992, 2004). Regardless of whether a difference of opinion concerns a highly sophisticated topic (e.g., a scientific dilemma) or a more mundane issue (e.g., a household chore), it is assumed that by means of a rational, reasonable, and critical discussion procedure, arguers ideally aim to arrive at a resolution of the difference of opinion at hand.

\footnotetext{
3 The increased focus on shared decision-making in modern medical practice derives from a number of sources (Charles et al. 1997, p. 681). For example, the ethical and legal concept of informed consent (American Medical Association 2010a). Informed consent can be defined as the "willing and uncoerced acceptance of a medical intervention by a patient after adequate disclosure by the physician of the nature of the intervention, its risks and benefits, as well as of alternatives with their risks and benefits" (Faden et al. 1986; Jonson et al. 2010). Informed consent seems to imply at least a minimum of shared decisionmaking in the form of the patient's consent to treatment prior to the intervention (Charles et al. 1997). Also increased interests in patient autonomy (excessively emphasized in the consumerism model), can be seen to have influenced the rise of shared decision-making as an ideal model of consultation.
} 
In order to elucidate what such a resolution-oriented approach to argumentative discourse precisely amounts to, in pragma-dialectics, an ideal model was developed in which the stages any argumentative discussion ideally proceeds through, as well as their corresponding speech acts, are specified. These stages comprise of a confrontation stage, in which the difference of opinion is defined, an opening stage, in which the point of departure of the discussion is established, an argumentation stage, in which arguments are exchanged, and a concluding stage, in which the outcome of the discussion is established. The basic principles underlying the moves made at the different stages of a critical discussion are represented by a set of ten dialectical commandments. Together, these commandments form the theoretical definition of a critical discussion and when they are not abided by, the resolution of the disagreement is said to be hindered or impeded. Such an impediment, in pragma-dialectics, is considered to be a fallacious move of argumentation. ${ }^{4}$

The ideal model of argumentative discussions developed within pragmadialectics provides the analyst of argumentative discourse with an analytical tool that is both normative and descriptive in nature. On the one hand, the model can be seen to serve as a blueprint of argumentative conduct, providing the criteria for a reasonable discussion on the merits. On the other hand, the ideal model can be used by the analyst to describe argumentative reality, using it as a grid of measurement. That is, argumentation in practice can be reconstructed and analyzed using the pragma-dialectical framework in order to describe the argumentative moves made by the discussants and, ultimately, to assess the extent of reasonable conduct demonstrated by the participants in the discussion.

Yet, in argumentative reality, participants in a discussion will usually not merely aim to argue reasonably. Arguers, in addition, will strive to persuade their audience in order to get their viewpoints, or standpoints, accepted. That is, typically, arguers do not solely aim for dialectical reasonableness, but they will also want to achieve rhetorical effectiveness. In order to account for arguers' dual argumentative aim, in pragma-dialectics, the notion of strategic maneuvering was introduced (van Eemeren 2010).

The concept of strategic maneuvering refers to arguers' continual efforts made in all moves carried out in argumentative discourse to keep a balance between reasonableness and effectiveness (van Eemeren 2010, p. 40). In pragma-dialectics, a distinction is made between three aspects of strategic maneuvering (van Eemeren 2010, p. 93). These aspects are each associated with distinct types of choices arguers make in maneuvering strategically. First, arguers will make an opportune selection from the topical potential available at a certain stage in the discussion (topical selection). That is, arguers will choose those argumentative moves that suit their purposes in the discussion best. Second, arguers will adapt their responses to meet audience demand - the audience's expectations and preferences (audience adaptation). Third, arguers will exploit the appropriate presentational devices available in phrasing their argumentative moves in the light of their discursive and stylistic

\footnotetext{
${ }^{4}$ For an overview of the pragma-dialectical discussion rules, their potential corresponding impediments (i.e., fallacious moves of argumentation), and the argumentative discussion stages see van Eemeren and Grootendorst (1992).
} 
effectiveness (argument presentation). Arguers, for instance, may make use of humor or figures of speech that they deem appealing to the public. It should be noted that the distinction between these three aspects of maneuvering is a mere analytic distinction. In practice, no maneuver can be made without making simultaneous choices regarding the topical potential, audience demand, and presentational devices (van Eemeren 2010) and only if these choices are thoroughly coordinated, it can be said that a full-blown discussion strategy has been employed. ${ }^{5}$

Although strategic maneuvering is primarily aimed at maintaining a balance between goals of reasonableness and effectiveness, this does not mean that arguers' argumentative moves in practice cannot be fallacious and, consequently, impede the resolution of the difference of opinion. The strategic maneuvers employed within a critical discussion may be off-balance as the participants may neglect either one of their argumentative aims: In argumentative practice, arguers may concentrate solely on the reasonableness of their arguments and thereby disregard their aim of persuasiveness. Although this can be considered a bad strategy, it is not a fallacious strategy (van Eemeren and Houtlosser 2002). Neglecting rules of reasonableness in favor of rhetorical goals, however, should be seen as a fallacious move, as within the pragma-dialectical theory of argumentation moves are only considered sound if they are in agreement with the dialectical rules for a critical discussion.

The introduction of the concept of strategic maneuvering to the pragmadialectical standard theory of argumentation has led to an extension of the theory that enables the analyst of argumentative discourse to do more justice to an argumentative reality in which arguers typically strive for dialectical as well a rhetorical success. Yet, in addition to this it should be emphasized that argumentation in practice does not occur in a contextual vacuum. Typically, the context in which argumentation takes place shapes the discussion significantly. Institutional rules, regulations, and norms offer opportunities and pose constraints on the ways in which discussion partners argue and, consequently, maneuver strategically. Therefore, it is of crucial importance that argumentative discourse is carefully situated by the analyst in the context in which it takes place. In the following, an argumentative characterization of doctor-patient consultation aimed at shared decision-making, as embedded within its institutionalized context, will be provided.

\section{An Argumentative Characterization of Medical Consultation}

Following the shared decision-making model, in medical consultation a doctor and his patient coequally strive to reach a treatment decision that will not only improve the patient's health, but that also meets both the doctor's and the patient's medical expectations and preferences regarding the treatment options available. If, in the process, any disagreement arises both parties are committed to resolving this

\footnotetext{
5 Coordinated strategic maneuvers can be said to be both vertically convergent and horizontally convergent. Vertical convergence means that all aspects of a strategic maneuver made reinforce each other. Horizontal convergence means that the separate maneuvers made in a certain stage, or in the discussion as a whole, reinforce each other when taken together (van Eemeren 2010, p. 47).
} 
difference of opinion in a reasonable and mutually respectful manner. By carefully negotiating treatment options during consultation, doctor and patient ideally should come to a treatment decision that is mutually shared.

Notably, the shared decision-making model shares its resolution-oriented stance with the pragma-dialectical model of a critical discussion (Snoeck Henkemans 2011). Both ideal models are based upon the assumption that conversational partners are essentially coequal partners that aim to resolve any difference of opinion that may arise in the course of their conversation on reasonable and rational grounds. Consequently, whenever a disagreement arises between a doctor and his patient, for instance about the applicability of antibiotics in case of an upper respiratory tract infection, the difference of opinion can be analyzed as an instantiation of a pragma-dialectical difference of opinion, embedded within a specific context-the context of medical consultation.

In accordance with the pragma-dialectical theory of argumentation, both doctor and patient can take up the role of protagonist of their own standpoint. In addition, they can both assume the role of antagonist casting doubt on (non-mixed difference of opinion) or openly rejecting (mixed difference of opinion) the opposing party's views. In a similar vein to in any other argumentative discussion, within the doctorpatient encounter a distinction can be made between four different discussion stages and, in addition, also the various (sub-)types of pragma-dialectical argumentation can be used by the discussion parties in support of their standpoints.

Although the shared decision-making model itself does not include an explicit normative body of rules, such as the ten context-independent commandments formulated in pragma-dialectics, a number of context-dependent rules, regulations, and norms can be distinguished that significantly shape the argumentative context of consultation and set this context apart from other argumentative contexts. Physicians' legal commitment to adhere to doctor-patient privilege and to maintain patient confidentiality is probably the most well-known regulation formulated within the medical domain. Disclosure of any confidential medical information inside and outside of the consultation is regarded a breach of both ethical and legal norms and is only allowed under specific circumstances (American Medical Association 2010b). However, this rule does not necessarily always affect the argumentative exchange in medical consultation. Doctors' legal obligation to inform the patient of all treatment options available, including the corresponding advantages and disadvantages, and to obtain consent for treatment prior to any form of medical care is likely to have a more immediate effect on doctors' and patients' argumentative exchanges in consultation. This legal doctrine of informed consent (see also footnote 4) lies at the basis of the shared decision-making model and implies that even when explicit opposition from the patient regarding the medical advice provided is lacking, a doctor should minimally assume critical doubt from the patient's side. As a result, under the rule of informed consent, doctors should always 'argue their case'.

Consistent with the process of informed consent, the patient or patient's surrogate decision-maker is free at all times to make the final decision regarding the treatment option of his choice-given that there are a number of equal options-or to even refuse care. This specific legal right implies that whenever a medical difference of 
opinion is not reasonably resolved, the patient holds the right to settle the difference of opinion in his own favor. If the doctor-for medical reasons-persists and refuses to comply with the patient's request, the physician is mandated to refer his patient to another doctor for a second opinion. Consequently, a return to the initial situation of the discussion is, due to institutional regulations, never possible in the context medical consultation aimed at shared decision-making.

Similar to in other discussion contexts, in the context of medical consultation discussion partners will select the most opportune arguments available and the most favorable means of presentation in order to convince their audience of the acceptability of their stance. Take, for example, a patient who has been suffering from repeated sore throats and has been actively seeking out to find more information about the source of his discomfort. He may come to the conclusion that antibiotics are the most effective solution to his problem, even though his doctor is hesitant as the patient's symptoms seem to be caused by a viral infection. The patient's and his doctor's standpoints clash. According to the pragma-dialectical theory of argumentation, they will ideally attempt to reasonably convince each other of the acceptability of their own standpoint in order to reach consensus. Yet, in addition, they will also want to resolve the difference of opinion in their own favor. In doing so, both the patient and his doctor will maneuver strategically and carefully select and phrase their arguments and adapt them to their specific audience, while aiming to remain within the bounds of the context-independent as well as the context-dependent rules for argumentative discourse.

In the following section, two case studies will be presented in order to illustrate how doctors and patients indeed maneuver strategically in actual consultation practice. Moreover, it will be aimed to show how the strategic maneuvers are inherently connected to the aims formulated in the shared decision-making ideal. In the two cases, young Tracey and Ali are brought to their doctors by their parents. ${ }^{6}$ Both children suffer from repeated sore throats caused by a tonsillitis, an upper respiratory tract infection. The parents prefer a treatment of the infection with antibiotics. Yet, their doctor opts for an alternate treatment method. An argumentative discussion emerges (Appendices 1 and 2).

\section{Arguing Antibiotics in Medical Consultation: Two Cases in Point}

Upper respiratory tract infections are the most commonly treated illnesses in the context of outpatient care (Meneghetti 2009). Ranging from the common cold to life-threatening illnesses, upper respiratory tract infections occur frequently among both adults and children. Especially the latter group is susceptible to tract infections such as rhinitis (inflammation of the internal nose), pharyngitis (inflammation of the throat), tracheitis (inflammation of the trachea), and tonsillitis (inflammation of the tonsils). The majority of upper respiratory tract infections in children are caused by

\footnotetext{
6 These cases were first presented in Elwyn et al. (1999), who studied these medical consultations taking a discourse analytic approach. Elwyn et al. purposefully selected these particular cases to highlight consultations in which 'conflict' occurs regarding the treatment of an upper respiratory tract infection.
} 
self-limiting viral infections. Yet, occasionally they can be caused by bacterial infections as well. As the symptoms of viral infections and bacterial inflammations are often similar, it can be difficult for a physician to immediately distinguish between the two and diagnose a patient without further investigation.

In the cases presented below, both young Tracey and Ali have been suffering from an upper respiratory tract infection. Repeated sore throats, caused by an inflammation of the tonsils, have been affecting their health considerably and they are brought to their general practitioner by either one (Tracey) or both (Ali) of their parents. Tracey and Ali's medical consultations are set within routine general practice sessions in an urban part of Cardiff, United Kingdom, and both transcripts record the first encounter between the patients and their physician. The general practitioner is the same in the two consultations and is known to have an interest in the involvement of patients in treatment decisions (Elwyn et al. 1999, p. 107).

The differences of opinion that arise between the doctor (D) and Tracey's mother (M) and Ali's father (F), who act as surrogate decision-makers within the consultation, concern the method of treatment for Tracey's and Ali's tonsillitis. Whereas in both cases the parent $(\mathrm{P})$ prefers a treatment with antibiotics, the physician opts for a different treatment method: a combination of acetaminophen and fluids. In both cases, the doctor and the parent each assume two standpoints that are juxtaposed (see Table 2). ${ }^{7}$ Both discussion partners act as a protagonist of their own standpoint and, additionally, they assume the role of antagonist of their opponent's contrasting standpoint. The differences of opinion that emerge in these two cases can, consequently, in accordance with the pragma-dialectical theory of argumentation be classified as multiple and mixed.

\subsection{Strategic Maneuvering in the Case of Tracey}

Tracey is brought to her physician by her mother, who is unmistakably worried about her eight-year-old daughter's repeated sore throats. Studying the transcript of the communicative interaction between $\mathrm{D}$ and $\mathrm{M}$, it becomes clear that $\mathrm{D}$ and $\mathrm{M}$ do not immediately agree upon the course of treatment of T's tonsillitis. In arguing for their treatment preferences, both parties maneuver strategically in order to

Table 2 Standpoints assumed by doctor (D) and Patient $(\mathrm{P})$ in the cases of Tracey (T) and Ali (A)

\begin{tabular}{|c|c|c|c|c|}
\hline $\mathrm{D}$ & $\begin{array}{l}\text { Acetaminophen is the } \\
\text { preferred method of } \\
\text { treatment for T/A's } \\
\text { tonsillitis }\end{array}$ & $\hookleftarrow \rightarrow$ & $\mathrm{P}$ & $\begin{array}{l}\text { Acetaminophen is not the } \\
\text { preferred method of } \\
\text { treatment for T/A's } \\
\text { tonsillitis }\end{array}$ \\
\hline \multirow[t]{2}{*}{ D } & $\begin{array}{l}\text { Antibiotics are not the } \\
\text { preferred method of } \\
\text { treatment for T/A's } \\
\text { tonsillitis }\end{array}$ & $\leftrightarrow \rightarrow$ & $P$ & $\begin{array}{l}\text { Antibiotics are the } \\
\text { preferred method of } \\
\text { treatment for T/A's } \\
\text { tonsillitis }\end{array}$ \\
\hline & \multicolumn{4}{|c|}{$\begin{array}{l}\text { [Either acetaminophen is the preferred } \\
\text { method of treatment for T/A's tonsillitis or } \\
\text { antibiotics is, but not both] }\end{array}$} \\
\hline
\end{tabular}

\footnotetext{
7 The representation of the multiple, mixed difference of opinion in Table 2 follows the format used by van Eemeren et al. (1993, p. 68).
} 
effectively convince their opponent of the acceptability of their views. As the various strategic maneuvers employed by $\mathrm{D}$ and $\mathrm{M}$ are often connected and mutually dependent, below the participants' maneuvers will be jointly discussed connecting them to the three main components of the shared decision-making ideal: (1) Doctor and patient are considered coequally involved experts, (2) they aim to build a consensus about the preferred treatment, and (3) the result is a treatment decision that is mutually shared.

\subsubsection{A Meeting of Coequally Involved Experts}

Within the shared decision-making model, physician and patient are considered coequal discussion partners that carefully weigh and discuss the treatment options possible before making a shared decision. Yet, even though the model advocates a process in which patients are active advocates of their own treatment preferences, explicit forms of medication-related pressure on doctors are still rare (Stivers 2002). Also within the case of Tracey, M seems to formulate her preference for antibiotics proactively but tentatively.

In the opening lines of the dialogue between D and M, M strategically steers the conversation towards the topic of antibiotics. By referring to a past experience with antibiotics, she can be seen to indirectly pressure (Stivers 2002) the doctor to prescribe her daughter Tracey a course of antibiotics.

\begin{tabular}{|c|c|c|}
\hline 005 & M & doctor A he's seen her last he gave her \\
\hline 006 & & one load lot of (.) antibiotics and then he gave me \\
\hline 007 & & a pre prescript repeat prescription then $(2.0)$ \\
\hline 008 & & to have the other to get it right out of the system \\
\hline
\end{tabular}

According to Stivers (2002), mentioning a past experience with antibiotic treatment forms one of four prominent ways for patients to explicitly communicate pressure for antibiotics. Whereas she considers requests or statements of desire to be relatively direct means of pressure, Stivers (2002) argues that referring to past experience, like inquiring about antibiotics, is a comparatively indirect method of pressure. "While it conveys a position in favor of antibiotics and overtly raises antibiotics for discussion, it does not explicitly state that preference and thus can be treated as simply providing information" (2002, p. 120). Indeed, at first glance, also M's contribution to her conversation with $\mathrm{D}$ seems to be a mere provision of information, a statement about her daughter's poor health. Yet, when closely examining the utterance, there appears to be more to her conversational contribution.

Following the pragma-dialectical theory of argumentation, M's assertion that doctor A prescribed Tracey antibiotics on a previous occasion should be analyzed as an authority-based argument for M's standpoint that antibiotics are the preferred method of treatment for T's tonsillitis - a standpoint that thus far has remained implicit and will continue to be so up until line 090. M's argument of past experience draws upon the authority of doctor A's medical expertise: doctor A, who 
is a medical expert as well as D, deemed antibiotics a suitable method of treatment in a similar situation. Consequently, $\mathrm{M}$ seems to argue, D should prescribe the medication this time too.

D's response to M's reference to her previous experience with doctor A, which from the perspective of strategic maneuvering can be analyzed as a topical choice on M's part, is particularly noticeable. In response to M's argument concerning doctor A, D turns to young Tracey and says:

$010 \quad$ D you're eight now how many times have you had

$011 \quad$ what we say is tonsillitis

Up until this point in the conversation, neither the term sore throat nor its medical counterpart tonsillitis has been used. As Tracey's sore throat is evidently audible, her condition has not been labeled as such. Remarkably, the first time her condition is mentioned explicitly, D uses medical jargon rather than layman's terminology. Although D does attempt to diminish the effect of his usage of a medical term by adding 'what we say', his rather complex formulation within the broader argumentative exchange can be analyzed as a deliberate presentational choice in reply to M's assertion about doctor A's assessment of Tracey's condition.

Using Latin terminology rather than ordinary arguers' language in response to M's argumentation, D presumably aims to indirectly convey his medical expertise. This intention is clearly distilled by $\mathbf{M}$, who subsequently aims to reinstate her credibility as an expert by communicating her understanding of the medical origin of Tracey's sore throats, referring to a speech therapist she consulted. A subdiscussion arises concerning the proposition that Tracey's tonsils are really enlarged (020-021):

\begin{tabular}{|c|c|c|}
\hline 019 & M & they said this when she went over for an examination \\
\hline 020 & & because she's seeing a speech therapist about her tonsils \\
\hline 021 & & being really enlarged \\
\hline 022 & $\mathrm{D}$ & they are rather enlarged but nothing out of the ordinary \\
\hline 023 & & lots of children have tonsils of this sort of size \\
\hline 024 & $\mathrm{D}$ & yeah okay (.) okay well the first thing to emphasize I guess \\
\hline 025 & & is that this is a sore throat (.) you're right to call it a tonsillitis \\
\hline 026 & & cos that's just a Latin name for a sore throat \\
\hline
\end{tabular}

D explicitly opposes M's sub-standpoint that Tracey's tonsils are enlarged by stating that 'they are rather enlarged but nothing out of the ordinary'. D, thereby, uses the technique of dissociation in order to frame M's sub-standpoint in his own favor: Tracey's tonsils are enlarged, but nothing out of the ordinary (022). Van Rees (2006, p. 477) states that "the rhetorical effect of dissociation in [such] a move is that the standpoint of the initial protagonist is set aside and replaced by a standpoint that is more to the liking of the antagonist", thereby simultaneously making it seem as if the protagonist was not precise enough. D supports his narrowed standpoint with the argument that 'lots of children have tonsils of this sort of size'. Following 
this short sub-discussion, D seems to aim to reinstate the relationship of mutuality between the two discussion partners and acknowledges M's expertise, stating 'you're right to call it a tonsillitis' $(025) .{ }^{8}$ Moreover, he also explains his earlier, somewhat paternalistic, usage of medical jargon by stating that tonsillitis 'is just a Latin name for a sore throat' (026).

\subsubsection{Building Consensus About the Preferred Treatment}

In the opening lines of the dialogue between $\mathrm{D}$ and $\mathrm{M}$, it thus becomes clear that $\mathrm{M}$ does not directly state her preference for antibiotics, but that she takes a more indirect approach by merely referring to her prior experience with her daughter's medical condition. Yet, it is not only the patient who advocates her standpoint regarding her preferred method of treatment indirectly. D as well only implicitly refers to the treatment option of his choice. His standpoint that a combination of acetaminophen and fluids is to be preferred over a course of antibiotics has to be inferred from the argumentation he advances (e.g., 052-055 and 058-068, 070-074 and 076-079).

While M's indirect, confrontational approach can be explained as an attempt to diminish her intrusion on the physician's medical expertise and authority in relation to prescribing decisions (Stivers 2002), an assumption that is emphatically supported by M's remark in line 043 ('I mean you are the doctor I'm not telling you your job'), D's silent confrontation can be explained from the perspective of the shared decisionmaking model. As the shared decision-making model promotes the involvement of both the patient and the doctor in the resolution process, each carefully weighing all arguments for the treatment options available, the doctor will most likely want to avoid presenting the matter as having been decided upon confrontation already-thereby respecting the patient's demand for autonomy. To cite Wolf (1988):

If the physician presents himself as certain of the one right course, and fails to divulge the range of options and the uncertainties that attend each, there is little to discuss. The conclusion seems to be foregone. Without knowledge of the alternatives, and without information about the pros and cons of each, the patient has no tools with which to enter the discussion in any meaningful way. The patient is effectively foreclosed from grappling with the treatment decision and reaching her own conclusion, whether it might be the same or different from the physician's. There is no opportunity for conflict over the proper treatment course because the decision-makers have been reduced from two to one. The patient is not operating as a decision-maker; the patient is being told what to do. (Wolf 1988)

It becomes clear from the above examples that, despite the fact that they use different strategies to do so, D and $\mathrm{M}$ both aim to communicate their authority and expertise within the consultation. They each maneuver strategically in their argumentation by selecting and presenting their arguments as such that they are adapted to their audience's demand. In doing so, the doctor and his patient try to establish their specific authority-roles of the evidence-based expert and the

\footnotetext{
${ }^{8}$ Note that, in contrast to what $\mathrm{D}$ suggests $\mathrm{M}$ has not used the term tonsillitis within the discussion.
} 
experience-based expert respectively. A continuous balancing act seems to be in play. While on the one hand the participants aim to share a decision, on the other hand, they also would like to see their own decision to be accepted. This act of balancing objectives is similar to that of pragma-dialectical discussants who, on the one hand, aim to resolve the difference of opinion at hand on reasonable grounds, yet, on the other hand, also preferably want to do so in their favor.

The participants' continuous efforts to establish a consensus, a decision that is shared and ideally also based upon their own convictions, is reflected in all stages of the argumentative discussion in consultation. A prominent strategy belonging to the opening stage of the discussion is to create a broad zone of agreement. Within the case of Tracey, D employs this strategy routinely. By explicitly asking for confirmation in response to his evidence-based arguments, he strategically adds to the shared set of starting points that exist between D and M, thereby steering the discussion in his own favor:

$\begin{array}{lll}028 & \text { D } & \text { okay (.) it's probably caused by repeated viruses (.) right } \\ 029 & \mathrm{M} & \text { right } \\ 030 & \mathrm{D} & =\text { like (.) repeated colds } \\ 031 & \mathrm{M} & \text { yes }\end{array}$

According to Stivers (2002, p. 1118), tokens such as okay and yes are typically used by parents when they agree to physician proposals of treatment. By using such tokens, thus, M explicitly appears to agree to D's arguments for a treatment with acetaminophen and thus gradually seems to bring the discussion closer to a 'shared' resolution. Besides explicit requests for confirmation, D also tries to broaden the zone of agreement by phrasing his arguments favorably. By presenting arguments as self-evident and as if they already belong to M's set of starting points, he strategically maneuvers the discussion in his favor. Some examples (italics added):

\begin{tabular}{|c|c|c|}
\hline 032 & $\mathrm{D}$ & $y^{\prime}$ know when you get a cold or a flu it's a virus \\
\hline 037 & & {$[\ldots]$ the difficulty with viruses is } \\
\hline 038 & & which I am sure you know is that \\
\hline 039 & & antibiotics (.) don't do a dickie bird for them \\
\hline 040 & & they don't wipe them out \\
\hline 041 & M & right $().[\ldots]$ \\
\hline
\end{tabular}

Adding to his explicit suggestion of shared medical knowledge saying 'I am sure you know' (038), D uses the colloquial expression 'don't do a dickie bird' (039) to enforce that $M$ will share his starting point that antibiotics do not affect viruses. Herewith, D seems to aim to mitigate the force of his argument by using humor and conveying solidarity, while at the same time strategically moving his argument to their shared set of propositions. Although in turn 041, M seems to agree with D's argumentation and politely uses the token of agreement 'right', her subsequent comments are not oriented towards a shared decision yet. Instead, she advances a 
new line of argumentation in which it appears that she wants the antibiotics to treat the side-effects rather than the tonsillitis itself.

M's attempt to establish authority and express her expertise within consultation is both reflected in the presentation of her standpoints and in the formulation of her arguments. While in the opening lines of the encounter, $M$ indirectly refers to her past experiences with consultation (e.g., experience with doctor A, speech therapy), tonsillitis (e.g., understanding of enlarged tonsils), and antibiotics (e.g., doctor A's repeat prescriptions), further on in their conversation $\mathrm{M}$ also refers to her past experience explicitly, often even adding degree adverbs such as 'guaranteed' and 'certainly' to add presentational strength to her arguments (italics added):

\begin{tabular}{|c|c|c|}
\hline 044 & M & I'd be guaranteed back tomorrow \\
\hline 045 & & because she seems to (.) this now is nothing \\
\hline 046 & & to how she usually goes down with it \\
\hline 080 & & she certainly reacts better (.) I would say so \\
\hline 081 & & out of experience \\
\hline 084 & & I (.) have given her paracetamol I was sent away \\
\hline 085 & & going back a while ago \\
\hline
\end{tabular}

$\mathrm{D}$, at the same time, asserts his medical expertise by advancing evidence-based argumentation (e.g., tonsillitis is caused by a virus, viruses are not affected by antibiotics, and scientific research is ambivalent about the effects of antibiotics on tonsillitis' side-effects). He uses a combination of symptomatic argumentationciting signs and symptoms of what is claimed in the standpoint- and pragmatic argumentation - referring to the positive or negative effects of a certain action(van Eemeren and Grootendorst 1992) to describe Tracey's medical condition and to argue his case in favor of acetaminophen. Remarkably, D often presents his arguments relatively tentatively (italics added):

\begin{tabular}{|c|c|}
\hline $034 \quad \mathrm{D}$ & it's probably caused by repeated viruses coming and going \\
\hline 058 & what I am saying I guess is that (.) \\
\hline 059 & the best guess we can do is that this is a viral illness \\
\hline 062 & some people like to have a course of antibiotics \\
\hline 063 & because they feel it makes a difference (.) and (.) \\
\hline 064 & the (.) science on this is a bit $50 / 50$ (.) \\
\hline 065 & sometimes it does (.) sometimes it doesn't (.) \\
\hline 066 & and as you've probably heard from the papers \\
\hline 067 & people are $a$ bit wary of giving antibiotics \\
\hline
\end{tabular}

D's presentational choices can be seen to serve several functions. First, and most prominently, D seems to leave room for M's interpretation and negotiationsomething that is deemed important from the perspective of shared decisionmaking. Especially his argument regarding scientific evidence ('sometimes it does, 
sometimes it doesn't') allows $\mathrm{M}$ an alternative interpretation. Second, D's cautious formulations can be analyzed to serve as a form of hedging. Although D presumes that Tracey is suffering from a viral infection, he cannot be absolutely certain. This small level of uncertainty is reflected in his choice of words: Tracey's sore throat is only 'probably' caused by a viral infection. Moreover, D's adverbs are used to soften his statements: $M$ has 'probably' read in the papers that people are 'a bit' wary of giving antibiotics. ${ }^{9}$ Lastly, D's quantifying adverbs also serve to emphasize that not everyone, and certainly not $\mathrm{D}$, is that keen on antibiotics, rather it is just 'some people'.

\subsubsection{Reaching a Treatment Decision That is Mutually Shared}

The second half of the consultation between D and M, from line 070 onward, is primarily concerned with resolving the difference of opinion and reaching a shared decision. In doing so, D uses some distinct presentational techniques in maneuvering strategically. By presenting the conclusion of the consultation as a characteristically and inherently shared endeavor, D makes a final attempt at reaching a resolution that is favorable to him personally while adhering to the ideal of shared decision-making. After having stressed that there are two options to choose from, using the plural pronoun we to emphasize D and M's shared decisive effort, D resumes his positively oriented pragmatic argument in support of acetaminophen (i.e., Tracey will build up natural immunity) and his negatively oriented pragmatic argument against a treatment with antibiotics (i.e., the tonsillitis will come back).

Although D's tactic seems a rhetorically strong and dialectically sound maneuver, $M$ is persistent and insists on treating Tracey with antibiotics (turns 080-081, 083). As a result, D seems to back down to allow a negotiated agreement (088, 'is that our preference?'), a settlement of the difference of opinion. In response, $\mathrm{M}$ too appears to aim to somewhat diminish her sturdy stance, by adding an additional argument in support of her case, based on what Stivers (2002) terms 'lifeworld circumstances':

096

097
M

'm (.) a busy person myself

back and forward to jobs you know

Yet, the difference of opinion is concluded and M's initial stance is accepted by D, even though the prescription seems 'interactionally driven' (cf., Stivers 2002), and thus settled, rather than reasonably resolved and based upon conviction on D's part.

\footnotetext{
${ }^{9}$ Following Elwyn et al. (1999, p. 110), the interview coincided with a wave of publicity concerning the overuse of antibiotics.
} 


\subsection{Strategic Maneuvering in the Case of Ali}

Like Tracey, two-year-old Ali (A) is brought to his doctor (D) by his parents. It is the first meeting between the family and their physician-the same as Tracey's. Ali has been suffering from tonsillitis, accompanied by a high temperature and vomiting. In the conversation with $\mathrm{D}$, the father $(\mathrm{F})$, who is a non-native speaker of English, takes up a leading role and should be seen as the protagonist of his family's views. Ali's mother $(\mathrm{M})$ remains within the background. Analyzing the transcript of the communicative interaction between $\mathrm{D}$ and $\mathrm{F}$ that is to result in a shared treatment decision, it becomes clear that $\mathrm{D}$ and $\mathrm{F}$ do not agree upon the course of treatment of A's tonsillitis. In negotiating their treatment preferences, both parties maneuver strategically in order to effectively convince their opponent of the acceptability of their views. The most prominent of these maneuvers will be discussed below.

\subsubsection{A Meeting of Coequally Involved Experts}

The medical encounter between $\mathrm{D}$ and $\mathrm{F}$ is not argumentative from the start. The first half of the consultation is predominantly dedicated to the exchange of information and a medical examination of young Ali's physique. F informs D that Ali has had a fever since the evening before and that he has lost his appetite. A short exchange follows in which D and F discuss Ali's symptoms. After D has examined Ali's ears, chest, and throat, D concludes that Ali is suffering from a sore throat, or tonsillitis:

$\begin{array}{lll}064 & \text { D } & {[\ldots] \text { so he's got um a sore throat }=} \\ 065 & \text { F } & =\text { I see } \\ 066 & \text { D } & \text { in medical terms we call it tonsillitis } \\ 067 & \text { F } & \text { yeah tonsillitis }\end{array}$

It can be argued that the argumentative discussion between $\mathrm{D}$ and $\mathrm{F}$ emerges from 075 onward. In the dialogue between $\mathrm{D}$ and $\mathrm{F}$ about how to deal with Ali's tonsillitis, it gradually becomes clear that a difference of opinion exists between the two men regarding the preferred method of treatment. From the onset, it is evident that $\mathrm{D}$ aims to take a mutuality-based approach to the decision-making process. In 076, D asks F directly whether he has any ideas about how to deal with the medical issue at hand ('did you have any ideas as to how we should deal with this problem?'). In response to this, F refers to his prior experience with the problem. Mentioning his older son, F aims to convey his understanding of the problem, but concludes saying 'I don't know anymore' (085).

Anticipating that $\mathrm{F}$ might request an antibiotic for his youngest son's condition, $\mathrm{D}$ then initiates the discussion advancing his first argument, supporting the standpoint that antibiotic are not a suitable method of treatment for Ali's sore throat. This argument is immediately followed by his standpoint regarding his preference for acetaminophen, and an argument: acetaminophen keeps the temperature down. 
Without further ado, D proceeds by returning to his initial argument that Ali is suffering from a viral infection:

$\begin{array}{ll}100 & \text { D } \\ 101 & \text { antibiotics as well (.) } \\ 102 & \text { but (.) I'm not so keen because } \\ 103 & \text { antibiotics don't deal with viruses }\end{array}$

In contrast to the case of Tracey, it is thus $\mathrm{D}$ who brings up the topic of antibiotics within the discussion. Apparently anticipating a request for the medication from $\mathrm{F}$, he explicitly states that he is not in favor of treating Ali's tonsillitis with antibiotics. Although D aims to diminish the effect of his directness by using the tentative formulation 'I'm not so keen' to advance his negative standpoint, he can be seen to have paved the way to openly discuss the option of antibiotics as a method of treatment with his patient's surrogate decision-maker.

After having added two evidence-based pragmatic arguments (antibiotics cause undesirable side-effects, antibiotics cause future problems, i.e., resistance) to his earlier symptomatic, and medically-grounded argument that tonsillitis is caused by a viral infection, D reaffirms the character of mutuality of the encounter in line 109 by explicitly asking which of the possibilities $\mathrm{F}$ would like to opt for. Both the usage of evidence-oriented argumentation and the explicit adherence to the shared decisionmaking ideal should be seen as topical choices that are adapted to F's demand for medical advice as well as autonomy.

Following D's invitation to take part in the decision-making process, F refers to his personal, prior experience with antibiotics stating that he feels that antibiotics will eliminate the problem shortly, while with acetaminophen the healing process will take longer. Something which is twice affirmed by D in turns 116 and 118 ('yes, takes a bit longer'). Then, F advances another personal, experience-based argument (or, cf., Stivers 2002, based on lifeworld experience), which is again confirmed by D:

\begin{tabular}{|c|c|c|}
\hline 120 & $\mathrm{~F}$ & [...] The parents we don't (1.0) \\
\hline 121 & & want to see our children (.) going done I mean getting weak \\
\hline 122 & $\mathrm{D}$ & [quietly $]$ sure $=$ \\
\hline
\end{tabular}

\subsubsection{Building Consensus About the Preferred Treatment}

$\mathrm{F}$, in response to D's confirmation, subsequently voices his preference for a treatment with antibiotics explicitly, stating a desire for the medication (123): 'we want to take some antibiotics'. Although a statement of desire is a relatively direct way of 'pressuring' a doctor to prescribe an antibiotic and is usually quite uncommon (Stivers 2002, p. 1116), in the interaction between D and F, D seems to have prepared the way for such a straightforward assertion by mentioning the medication himself.

After F's explicit statement of desire, D notably asks his patient's surrogate decision-maker twice for a confirmation (125-127). In reaction to this, F suddenly 
decides to communicate his willingness to compromise his standpoint in order to reach a solution that is acceptable to the doctor too. He states that, if encouraged by his doctor, he could also take the acetaminophen instead of the antibiotics (129-130). Strategically, D then reiterates his standpoint-presenting it as a personal feeling rather than an evidence-based fact-and repeats his pragmatic arguments concerning the negative side-effects antibiotics may have (134-138).

It should be noted that vomiting, one of the side-effects D refers to in response to F's renewed willingness to negotiate, is in fact one of the primary symptoms that lead $\mathrm{F}$ to taking his son to consultation in the first place. The fact that $\mathrm{D}$ reemphasizes the existence of negative side-effects should thus be seen as an opportune topical choice within the discussion. D's initial argument that tonsillitis is caused by a viral infection is, notably, not restated as D and F could not agree upon that at an earlier stage of the discussion.

\subsubsection{Reaching a Treatment Decision That is Mutually Shared}

Not surprisingly, F uses a token of agreement ('I see, yeah I understand') to show his acceptance of D's strategically selected and formulated arguments concerning the possible undesirable side-effects of antibiotics. In doing so, $F$ adds the information communicated within D's arguments to their shared set of starting points. Building forth on the starting points added, D emphasizes the patient's right of participatory decision-making and autonomy one last time. Yet, by strategically phrasing his utterance, the possibility for $\mathrm{F}$ to voice his opposing stance becomes relatively small, as it would require him to openly reject D's standpoint and, consequently his authority, once more (italics added):

\begin{tabular}{|c|c|}
\hline $141 \quad \mathrm{D}$ & um (.) but if you feel strongly \\
\hline 142 & that you would like to definitely have an antibiotic \\
\hline 143 & we can do that as well (.) \\
\hline
\end{tabular}

Following these utterances, D provides $\mathrm{F}$ with a third option, that of delayed prescription (144-146). Although this offer is recognized by $F$ with a token of acknowledgement ('I see, yeah'), the option is ignored by $\mathrm{F}$ and $\mathrm{M}$ in their subsequent sub-discussion concerning the different methods of treatment. After a short 'sharing' of the decision between F and M, F finally concludes the difference of opinion stating that he would like to treat his son with acetaminophen 'this time'. $\mathrm{D}$ pursues the sharing of treatment decisions by asking which acetaminophen $\mathrm{F}$ prefers, but F seems to have 'surrendered' to D and leaves the final decision up to him. In contrast to Tracey, Ali thus does not receive the treatment of his parent's initial preference. From the transcript, it appears that $F$ is convinced of the acceptability of D's standpoints. Rather than settled-as seems to be the case in Tracey's consultation - the difference of opinion between $D$ and $F$ is thus reasonably resolved in favor of $\mathrm{D}$. 


\section{Conclusion}

Over the past decades, the model of shared decision-making has been increasingly advocated as the preferred standard of doctor-patient communication. Yet, shared decision-making is not always an easy process. Shared decision-making can become problematic when a method of treatment is actively advocated by the patient-or the patient's surrogate decision-maker-that is not appropriate. A course of antibiotics is such method of treatment that is frequently requested inappropriately (e.g., in the absence of a bacterial infection).

In this paper, it was examined how in pediatric medicine argumentative discussions can arise between physicians and parents concerning the treatment of a young child that is suffering from a tonsillitis. It was studied how doctor and patient negotiate their treatment preferences and decisions by means of a resolutionoriented discussion process. Two cases were studied in an effort to illustrate how the participants within argumentative consultation maneuver strategically in order to maintain a balance between dialectical reasonableness and rhetorical effectiveness (cf., the extended pragma-dialectical theory of argumentation), as well as an equilibrium between patient participation and evidence-based medication (cf., the shared decision-making ideal).

While earlier research carried out in the field of health communication predominantly focused on conversation and discourse analytic aspects of the doctor-patient encounter, in this paper a pragma-dialectical perspective was chosen-a perspective that proved insightful to the study of doctor-patient consultation and the treatment negotiation process facilitated by the shared decision-making model. Adding to recent endeavors in pragma-dialectics to study argumentative discourse in the specific context it occurs in, in this paper the argumentative exchanges of doctors and their patients set in the specific context of shared decision-making were taken as a starting point.

The cases of Tracey and Ali, which were taken from Elwyn et al. (1999), elaborately illustrated the insights an integrated pragma-dialectical analysis provides analyzing the discourse of consultation and shared decision-making. A reconstruction was made of the argumentative discussion that emerged in both cases between the doctor and his patient's surrogate decision-maker, the parent, concerning the treatment of an upper respiratory tract infection. It became clear that the discussants in actual consultation indeed maneuver strategically in an attempt to remain within the realm of the dialectically reasonable. But more importantly, it was also illustrated that their strategic maneuvers were connected to the objective of participatory decision-making. That is, recurrently, both doctor and patient aimed in their maneuvers to communicate their intent to share the decision. In addition to that, they repeatedly focused on their own capability of sharing such treatment decision by emphasizing their evidence-based and experience-based authority respectively. These findings could serve as a starting point for further research focusing on the evaluation of the soundness of the maneuvers employed.

It should be noted that, evidently, the two cases of antibiotic-related difference of opinion in consultation presented in this paper are not representative of all medical consultations in which shared decision-making takes place. First, and foremost, the 
two cases are set within the context of pediatric medicine and both concern an upper respiratory infection in a child for which a course of antibiotics is requested by the parent. Since in pediatrics the parents typically take up the role of a surrogate decisionmaker, the doctor does not directly interact with his patient, but with his patient's parent. This may have affected the argumentative interaction slightly. Further research should consequently focus on other medical contexts in which the physician directly interact with their primary patients, such as for example acute medicine, as well. Additionally, also the fact that one of the patient's surrogate decision-maker was not a native speaker of English, the language of the consultation, may have affected the argumentative interaction to a certain extent. Lastly, it should be noted that the two cases discussed in this paper were transcribed by Elwyn et al. (1999) and the original tape recordings were not used for the present pragma-dialectical analysis.

Despite the relatively small scope of this study and its limitations discussed in the above, the present paper provides new insights in a field of studies that has recently received an increasing amount of both scholarly and popular interest. The topic of antibiotics specifically seems indisputably relevant. In recent years, the overuse of antibiotics has become a recurrent issue of concern and over-prescription due to patient pressure seems to be one of its major causes. In this paper, it has been aimed to show that the study of argumentation theory can shed new light on the issue of antibiotics-related disagreement in consultation and potentially provide a starting point for teaching physicians how to support their treatment advice. For, whereas traditionally a doctor's medical and paternalistic 'verdict' used to suffice, the modern doctor not only needs to diagnose his patient, but he also has to argue his case.

Acknowledgments The author would like to thank Dr. Francisca Snoeck Henkemans for her comments on an earlier version of this paper. In addition, the author thanks Dr. Glyn Elwyn for the permission to make use of the two case studies ("Tracey" and "Ali") presented in this paper.

\section{Appendix 1: Transcript of consultation-Tracey (cf., Elwyn et al. 1999)}

\begin{tabular}{|c|c|c|}
\hline (.) & \multicolumn{2}{|c|}{ brackets containing a stop indicate a pause of less than two seconds } \\
\hline (2) & \multicolumn{2}{|c|}{ numerals in round brackets indicate the length in seconds of other pauses } \\
\hline [] & \multicolumn{2}{|c|}{ square brackets contain relevant contextual information or unclear phrases } \\
\hline [.] & \multicolumn{2}{|c|}{ italicized square brackets describe a non-verbal utterance } \\
\hline[ & \multicolumn{2}{|c|}{ this symbol in between lines of dialogue indicates overlapping speech } \\
\hline : & \multicolumn{2}{|c|}{ a colon indicates elongation of the preceding sound } \\
\hline$=$ & \multicolumn{2}{|c|}{ an equal sign means that the phrase is contiguous with the preceding one without pause } \\
\hline 001 & $\mathrm{D}$ & Tracey you're eight now is that right? \\
\hline 002 & & [inaudible: sore throat evidently the matter] \\
\hline 003 & M & she:'s suffering a lot from it um (.) \\
\hline 004 & & she always seems to be on antibiotics um (2.0) \\
\hline 005 & & doctor A he's seen her last he gave her \\
\hline 006 & & one load lot of (.) antibiotics and then he gave me \\
\hline
\end{tabular}


007

008

009

010

011

012

013

014

015

016

017

018

019

020

021

022

023

[further examination takes place]

024

D

025

026

027

028

029

030

031

032

033

034

035

036

037

038

039

040

041

042

043

044

M a pre prescript repeat prescription then (2.0)

to have the other to get it right out of the system

[talks to child]

[to Tracey] you're eight now how many times have you had what we say is tonsillitis?

I'd say (.) about every two and a half months

every two and a half months

[muttering]

is it stopping you going to school?

it is is it?

can I take a look in your throat (.)

please (.)

have you had this done before?

(6.0)

they said this when she went over for an examination

because she's seeing a speech therapist about her tonsils

being really enlarged

they are rather enlarged but nothing out of the ordinary

lots of children have tonsils of this sort of size

yeah okay (.) okay well the first thing to emphasize I guess

is that this is a sore throat (.) you're right to call it a tonsillitis cos that's just a Latin name for a sore throat

right

okay (.) it's probably caused by repeated viruses (.) right $=$

right

$=$ like (.) repeated colds

yes

y'know when you get a cold or a flu it's a virus

chicken pox measles they're viruses

(.)

it's probably caused by repeated viruses coming and going

contact with other children contact with school

sometimes you leave a virus hanging around in your body

and reactivating (.) the difficulty with viruses is

which I'm sure you know is that

antibiotics (.) don't do a dickie bird for them

they don't wipe them out

right (.) the trouble is (.)

I could go away from here tomorrow

I mean you are the doctor I'm not telling you your job

but I'd be guaranteed back tomorrow 
045

046

047

048

049

050

051

052

053

054

055

056

057

058

059

060

061

062

063

064

065

066

067

068

069

070

071

072

073

074

075

076

077

078

079

080

081

082

083

084

085

086

087

088 because she seems to (.) this now is nothing

to how she usually goes right down with it

as well you know second third

with a high temperature

becomes very ill $=$

$=$ that's right

sure (.) yeah (.) and some people find that (.)

antibiotics help them through that illness

if they extend their

[

yes

(.)

what I am saying I guess is that (.)

the best guess we can do is that this is a viral illness

that it won't respond to antibiotics

it'll just (.) take its time and get better (.)

some people like to have a course of antibiotics

because they feel it makes a difference (.) and (.)

the (.) science on this is a bit 50/50 (.)

sometimes it does (.) sometimes it doesn't (.)

and as you've probably heard from the papers

people are a bit wary of giving antibiotics

[

M

that's right yes $=$

$=$ yeah (.) so (.) we've got two choices (.) all right now?

these are the two choices (.)

we'll give you plenty of paracetamol (.) fluids

and let this illness carry on

and build up a natural immunity (.) yeah? =

$=$ all right

or we'll give you some antibiotics (.) and (.)

treat it as we treated it in the past

although as you say (.) it (.) keeps coming back

and I don't think we can stop that

no (.) she certainly reacts better (.) $I$ would say so

out of experience

to?

the antibiotics really do seem to work on her

I (.) have given her paracetamol I was sent away going back a while ago (.) to give her [parroting]

paracetamol plenty of fluids (.) she was burning up (.) ah no (.)

she (.) it seemed to drag along a long way you know

is that our preference? (.) to: have a go with some antibiotics 
089

090

091

092

093

094

095

096

097

098

099

100

101

102

103

104

rather than try the paracetamol and $=$ [telephone rings through following turn] $=\mathrm{I}$ 'd rather the antibiotics

D yeah?

M really (.) I would

I mean if there was a way I thought she was going to be all right in a couple of days (.) I know it sounds awful if I've got the antibiotics into her I'm (.)a busy person myself I'm (.) back and forward to jobs you know and I can't [laughing] I know that sounds awful but (.) the antibiotics definitely do work better on her (.) I would say so

D excuse me a second [answers phone] yes okay um (.) have you found any particular one to be more helpful than any other?

M umm: (.) the clear one

\section{Appendix 2: Transcript of consultation-Ali (cf., Elwyn et al. 1999)}

\begin{tabular}{|c|c|c|}
\hline 001 & $\mathrm{D}$ & okay how can I help? \\
\hline 002 & $\mathrm{~F}$ & yeah (.) he has a high fever (.) \\
\hline 003 & & since eight o'clock yesterday night \\
\hline 004 & & and he has vomited yesterday night \\
\hline 005 & & and in the morning again (.) \\
\hline 006 & & he:: doesn't eat anything (.) \\
\hline 007 & & refuses everything (.) \\
\hline 008 & & and (.) he's weak (.) \\
\hline 009 & & since (.) two days \\
\hline 010 & $\mathrm{D}$ & weak yes \\
\hline 011 & $\mathrm{~F}$ & yeah \\
\hline 012 & $\mathrm{D}$ & (.) has he um had a temperature \\
\hline 013 & $\mathrm{~F}$ & [M assenting] yes uh thirty eight \\
\hline 014 & $\mathrm{D}$ & thirty eight \\
\hline 015 & $\mathrm{~F}$ & yeah \\
\hline 016 & $\mathrm{D}$ & for how long? \\
\hline 017 & & $(2.0)$ \\
\hline 018 & $\mathrm{~F}$ & yesterday night since yesterday night \\
\hline 019 & M & [almost inaudible: all day] \\
\hline 020 & $\mathrm{~F}$ & [quietly] okay \\
\hline 021 & $\mathrm{D}$ & has he carried on eating or not eating \\
\hline 022 & $\mathrm{~F}$ & not eating anything \\
\hline
\end{tabular}




\begin{tabular}{|c|c|c|}
\hline 023 & M & [quietly] not eating \\
\hline 024 & $\mathrm{D}$ & vomiting? \\
\hline 025 & $\mathrm{~F}$ & vomiting that's right yeah $=$ \\
\hline 026 & $\mathrm{D}$ & $=$ yeah? (.) any diarrhea? \\
\hline \multirow[t]{2}{*}{027} & $\mathrm{~F}$ & no diarrhea at all \\
\hline & & {[} \\
\hline 028 & M & no \\
\hline 029 & $\mathrm{D}$ & any coughing? [simulates sound of coughing] \\
\hline 030 & $\mathrm{~F}$ & no at all \\
\hline 031 & $\mathrm{D}$ & not all all \\
\hline 032 & $\mathrm{~F}$ & not at all \\
\hline 033 & M & [quietly] not at all \\
\hline 034 & $\mathrm{D}$ & okay \\
\hline 035 & & (.) \\
\hline 036 & $\mathrm{~F}$ & not at all not at all \\
\hline 037 & $\mathrm{D}$ & okay (.) I'd like to just have a look at him \\
\hline 038 & $\mathrm{~F}$ & okay \\
\hline 039 & $\mathrm{D}$ & right you keep him on your lap there and I'll (.) \\
\hline 040 & & [to Ali] hullo (.) what's your name? (.) Ali yeah? \\
\hline \multirow[t]{2}{*}{041} & & (.) maybe if we take the jersey off first of all \\
\hline & & 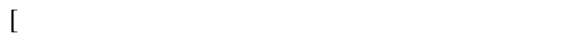 \\
\hline 042 & $\mathrm{~F}$ & yeah \\
\hline 043 & $\mathrm{D}$ & (3.0) how old is Ali now? \\
\hline 044 & $\mathrm{~F}$ & (.) two years and (.) eight months \\
\hline 045 & $\mathrm{D}$ & two years and eight months okay \\
\hline 046 & & I'll listen to the chest first if I may (2.0) \\
\hline 047 & $\mathrm{~F}$ & okay [three syllables to A] \\
\hline 048 & & (18.0) [D examines Ali's chest] \\
\hline 049 & $\mathrm{D}$ & yes he's quite hot \\
\hline 050 & $\mathrm{~F}$ & yeah uh do you know I've realized that uh \\
\hline 051 & & he has uh very big tonsils? \\
\hline 052 & & $(5.0)$ \\
\hline 053 & $\mathrm{D}$ & the other side (.) \\
\hline 054 & & let's have a look in this ear as well \\
\hline 055 & & (7.0) [D unwraps tongue depressor] \\
\hline 056 & $\mathrm{~F}$ & open your mouth ah:: ah:: ah:: \\
\hline 057 & $\mathrm{D}$ & very good \\
\hline 058 & $\mathrm{~F}$ & good \\
\hline 059 & $\mathrm{D}$ & thank you \\
\hline 060 & & $(2.0)$ \\
\hline 061 & & right (3.0) it's very clear what he's got \\
\hline 062 & & he's got some white spots on his tonsils = \\
\hline 063 & $\mathrm{~F}$ & $=\mathrm{I}$ see \\
\hline 064 & $\mathrm{D}$ & yeah? so he's got um a sore throat $=$ \\
\hline
\end{tabular}


065

066

067

068

069

070

071

072

073

074

075

076

077

078

079

080

081

082

083

084

085

086

087

088

089

090

091

092

093

[...]

100

101

102

103

104

105

106

107

108

109

110

111
F

D

F

D

F

D

F

D

F

D

F

D

D

F

D
D

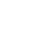

]

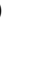

2

3

4

7

9

$=$ I see

in medical terms we call it tonsillitis

yeah tonsillitis

$=$ okay (.) his ears are fine

yeah

chest is fine

okay thanks very much $=$

$=$ so that's why he's got a high temperature

okay? =

= okay thank you

(.)

now (2.0)

did you have any ideas as to how we should deal with this (.) problem?

actually I have a (.) other son [D: $\mathrm{mmm}$ ] (.)

six and a half years old [D: mmm] (.) he had

lots of problem (.) about his tonsils (.)

the same problem (.) actually he [all come?] now

he finished this problem (1.0) he's coming to age seven

(.) so (.) I think it is better to keep the child from cold

(.) no cold drinks? something like that (.)

I don't know any more

okay (.) the the ways we deal with tonsillitis (.) um (.)

it's quite normal for children to have this kind of problem

(.) yeah? d'ya?

yes $=$

$=$ it comes and goes it's usually a viral infection

a virus okay? (.)

which means that (1.0) I would like to u::se (.)

either Disprol or Calpol to keep the temperature down

right? (.) now (.) some people then (.) like to use (.)

antibiotics as well (.)

but (.) I'm not so keen because

antibiotics don't deal with viruses (.)

they just (.) are no use (1.0)

and they also cause some problems (.)

they sometimes cause diarrhea and vomiting (.) um (.)

and it means that you have (.) problems for the future (1.0)

so (.) those are the kind of possibilities (1.0)

which (.) which way would you like to deal with the problem?

(1.0)

actually if I use antibiotics for my children (.) 
112

113

114

115

116

117

118

119

120

121

122

123

124

125

126

127

128

129

130

131

132

133

134

135

136

137

138

139

140

141

142

143

144

145

146

147

148

149

150

151

152
D

F

D

F

D

F

D

F

D

F

D

F

D

D

D

F

D the problem (.) is ending in a short time (.)

which I ha ob observe (.) but the the another way (.)

some paracetamol or things yeah (1.0)

it will end but a little bit more than the uh (.)

yes take a bit longer $=$

$=$ yeah take longer

sure I understand ((yeah))

(1.0)

so it's it's uh (.) family I mean the parents we don't (1.0)

want to see our children (.) going down I mean getting weak

[quietly] sure $=$

$=$ so we want to take some (.) antibiotics

(1.0)

you would like to do that would you?

[

yeah

yeah?

yeah (.) it is too difficult to to explain but (2.0)

if we can uh (2.0) can be encouraged by doctors yeah

we can do some uh paracetamol

sure $=$

= we cannot lie

(.)

my own feeling is that

you're probably better to use paracetamol and fluids

rather than use antibiotics

because you can cause sickness

and also resistance for the future

[

I see

yeah I understand

um (.) but if you feel strongly

that you would like to definitely have an antibiotic

we can do that as well (.)

um the other possibility 's for me to give you

a prescription for an antibiotic

and for you to wait

I see (.) yeah

[

and and only use it

if things get worse

you can give me a telephone call or something

yeah (.)

so which one of these possibilities would you like to do> 
153

154

155

156
(1.0)

$\mathrm{F}$

okay [slight laughter in voice] let me ask my wife

[to M] which one paracetamol or (.) antibiotics?

(.) antibiotics?

[After a subdued and brief laugh, $\mathrm{M}$ responds to $\mathrm{F}$ at some length in their own language, quietly and insistently]

\begin{tabular}{|c|c|c|}
\hline 157 & $\mathrm{~F}$ & yeah paracetamol this time please [M still talking quietly to $\mathrm{F}$ ] \\
\hline 158 & $\mathrm{D}$ & okay (2.0) Disprol or Calpol? \\
\hline 159 & $\mathrm{~F}$ & yeah \\
\hline 160 & $\mathrm{D}$ & which one? doesn't matter \\
\hline 161 & $\mathrm{~F}$ & $\begin{array}{l}\text { I see uh Calpol is uh eh better than paracetamol or euh which one? } \\
\text { [M whispers to F throughout] }\end{array}$ \\
\hline 162 & $\mathrm{D}$ & children like it a bit better than most stuff [laughing] \\
\hline 163 & M & yeah $=$ \\
\hline 164 & $\mathrm{~F}$ & $=$ okay \\
\hline & & {$[\ldots]$} \\
\hline 175 & M & thank you very much \\
\hline 176 & $\mathrm{D}$ & no problem and he's you know he'll be healthy fine \\
\hline 177 & $\mathrm{~F}$ & okay \\
\hline 178 & $\mathrm{D}$ & okay no problem \\
\hline 179 & M & thanks very much \\
\hline 180 & $\mathrm{D}$ & bye bye now \\
\hline 181 & $\mathrm{~F}$ & bye bye \\
\hline & & {[} \\
\hline & M & bye \\
\hline
\end{tabular}

\section{References}

American Medical Association. 2010a. Informed consent. http://www.ama-assn.org/ama/pub/physicianresources/legal-topics/patient-physician-relationship-topics/informed-consent.shtml. Accessed May 2011.

American Medical Association 2010b. Patient confidentiality. http://www.ama-ssn.org/ama/pub/ physician-resources/legal-topics/patient-physician-relationship-topics/patient-confidentiality.shtml. Accessed May 2011.

Charles, C.A., A. Gafni, and T. Whelan. 1997. Shared decision-making in the medical encounter: What does it mean? (Or it takes at least two to tango). Social Science and Medicine 44(5): 681-692.

Charles, C.A., A. Gafni, and T. Whelan. 1999. Decision-making in the physician-patient encounter: Revisiting the shared treatment decision-making model. Social Science and Medicine 49: 651-661.

Charles, C.A., T. Whelan, A. Gafni, A. Willan, and S. Farrell. 2003. Shared treatment decision-making: What does it mean to physicians? Journal of Clinical Oncology 21(5): 932-936.

Edwards, A., and G. Elwyn. 2009. Shared decision-making in health care: Achieving evidence-based patient choice. Oxford: Oxford University Press.

Elwyn, G., R. Gwyn, A. Edwards, and R. Grol. 1999. Is 'shared decision-making' feasible in consultations for upper respiratory tract infections? Assessing the influence of antibiotic expectations using discourse analysis. Health Expectations 2: 105-117.

Faden, R.R., T.L. Beauchamp, and N.M.P. King. 1986. A history and theory of informed consent. New York, NY: Oxford University Press.

Gwyn, R., and G. Elwyn. 1999. When is a shared decision not (quite) a shared decision? Negotiating preferences in a general practice encounter. Social Science and Medicine 49: 437-447. 
Heritage, J., and D.W. Maynard. 2006. Problems and prospects in the study of physician-patient interaction: 30 years of research. Annual Review Sociology 32: 351-374.

Jonson, A., M. Siegler, and W.J. Winslade. 2010. Clinical ethics: A practical approach to ethical decisions in clinical medicine, 7th ed. New York, NY: McGraw-Hill.

Maynard, D.W., and J. Heritage. 2005. Conversation analysis, doctor-patient interaction and medical communication. Medical Education 39: 428-435.

Meneghetti, A. 2009. Upper respiratory tract infection. http://emedicine.medscape.com/article/302460overview. Accessed May 2011.

Ong, L.M.L., J.C.J.M. de Haes, A.M. Hoos, and F.B. Lammes. 1995. Doctor-patient communication: A review of the literature. Social Science and Medicine 40(7): 903-918.

Pilgram, R. 2009. Argumentation in doctor-patient interaction: Medical consultation as a pragmadialectical communicative activity type. Studies in Communication Sciences 9(2): 153-169.

Roter, D.L., and J.A. Hall. 1989. Studies of doctor-patient interaction. Annual Review Public Health 10: $163-180$.

Roter, D.L., and J.A. Hall. 2006. Doctors talking with patients/patients talking with doctors: Improving communication in medical visits, 2nd ed. Westport, CT: Praeger.

Roter, K.S., and D.L. McNeilis. 2003. The nature of the therapeutic relationship and the assessment of its discourse in routine medical visits. In Handbook of health communication, ed. T.L. Thompson, 121-162. Mahwah, NJ: Lawrence Erlbaum.

Snoeck Henkemans, A.F. 2011. Strategic maneuvering by physicians in a shared decision making process. In Proceedings of the 7th international conference for the study of argumentation, ed. F.H. van Eemeren, B.J. Garssen, D. Godden, and G. Mitchell. Amsterdam: Rozenberg/Sic Sat.

Stivers, T. 2002. Participating in decisions about treatment: Overt parent pressure for antibiotic medication in pediatric encounters. Social Science and Medicine 54: 1111-1130.

van Eemeren, F.H. 2010. Strategic maneuvering in argumentative discourse: Extending the pragmadialectical theory of argumentation. Amsterdam: John Benjamins.

van Eemeren, F.H., and R. Grootendorst. 1984. Speech acts in argumentative discourse: A theoretical model for the analysis of discussions directed towards solving conflicts of opinion. Dordrecht: de Gruyter.

van Eemeren, F.H., and R. Grootendorst. 1992. Argumentation, communication, and fallacies. Hillsdale, NJ: Lawrence Erlbaum.

van Eemeren, F.H., and R. Grootendorst. 2004. A systematic theory of argumentation: The pragmadialectical approach. Cambridge: Cambridge University Press.

van Eemeren, F.H., R. Grootendorst, S. Jackson, and S. Jacobs. 1993. Reconstructing argumentative discourse. Tuscaloosa, AL: University of Alabama Press.

van Eemeren, F.H., and P. Houtlosser. 2002. Strategic maneuvering: Maintaining a delicate balance. In Dialectic and rhetoric: The warp and woof of argumentation analysis, ed. F.H. van Eemeren and P. Houtlosser, 131-159. Dordrecht: Springer.

van Rees, M.A. 2006. Strategic maneuvering with dissociation. Argumentation 20: 473-487.

Wolf, S.M. 1988. Conflict between doctor and patient. Law, Medicine and Health Care 16(3/4): 197-203. 